\title{
Simulation Study of Spot Weld Material Configurations for Crash Analysis
}

Sachin Pati"* and Hamid M Lankarani

Wichita State University, Wichita, KS, USA

\begin{abstract}
In engineering practice, spot welds are normally not modeled in detail, but as connection elements which transfer forces and moments. Therefore a proper methodology for the development detailed weld model to study structural response of the weld when the applied load range is beyond the yield strength discussed in this paper. Threedimensional finite element (FE) models of spot welded joints are developed using LS-Dyna. Simple spot weld models are developed based on the detailed model behavior developed earlier. In order to generate testing data, virtual tensile testing simulations are carried out with mesh sensitivity in the necking zone. This high mesh resolution around necking zone is required to capture the steep gradients in the pressure and stress tri-axility, etc. Once the stress strain curves are generated in the simulations examined damage function and evolution to represent failure. Various EHSS steels grades used in this study. The results from this study shows reasonable agreement between the simulations and the test results. Hence, spot weld model obtained should be considered for crash analysis applications to understand behaviors of structural parts.
\end{abstract}

Keywords: Finite element; spot weld; T-joint specimen; weld characterization; EHSS steel

\section{Introduction}

For structural parts of vehicle body, the yield stress is usually a more important property than the tensile strength, since once it is reached, the structure deforms beyond acceptable limits. The response of a structure under load depends to a large extent on the stress-strain relation of the constituent materials and the magnitude of stress. The yield stress measures the resistance to plastic deformation. Beyond the yield strength, the stress-strain relation exhibits strain hardening until failure.

The present study has been conducted using the LS-Dyna in order to investigate this key question of weld behavior. This work is further focuses on acceptance of a B-pillar system subjected to side impact. The key methodological evolution on the spot weld behavior is combined with a study on weld of $\mathrm{T}$-joint specimen of a prototypical B-pillar system.

\section{RSW Modeling Studies Review}

Spot welding is the primary joining method used for the construction of the automotive body structure made of steel. A major challenge in the crash simulation today is the lack of a simple yet reliable modeling approach to characterize spot weld separation.

Various approaches for Numerical simulation of spot welding have been discussed by [1-4]. A study of a spot weld for numerical analysis of automotive applications under crash loading conditions using validation model 3 point- bend test were studied by Sebastian et al. [5]. Hardness in the heat-affected zone and stresses are studied [6-9] that exhibit sharp hardness change adds to brittleness and notch sensitivity. Lee et al. [10] and Chao [11] have studied the ultimate tensile strength of resistance spot welds in mild steel subjected to combined loading tension and shear loads. Detailed solid element simulations of local spot weld deformation under various loads provide rationale for the experimental observations and model simplifications discussed in paper by Deng et al. [12]. Schweizerh et al. [13] has discussed mesh sensitivity in spot weld modeling. Failure model parameters are derived from Finite element method (FEM) test simulations [14] since it's difficult to measure of local properties in spot welds.

The present work deals with a complete study on identification and modeling of spot weld connections. Relatively few studies have been conducted on the failure model of a spot weld under impact loading conditions whereas quasi-static cases are found more often. Most of studies are based on AHSS, DP 600 material as spot-weld and those sources do not show that EHSS steel materials sheet metal spot welding. In this study, the mechanical properties and spot weld-ability of newly developed EHSS steels are discussed which are widely used in automotive crash area with high energy intake e.g., front rails, sill, crash box, etc. The separation criteria are implemented into a commercially available explicit finite element code.

\section{Methodology}

In this study, the mechanical properties and spot weld-ability of newly developed steels are discussed [15]. All of the specimens are made of high-strength steel (EHSS) sheet metal of the same thickness of $1.2 \mathrm{~mm}$. This steel is having yield strength $368 \mathrm{Mpa}$ close to Dual phase DP600 but lower tensile strength. The high-strength steel materials HSLA340 showed a mutually comparable strength at quasistatic loading [16]. Uniaxial tensile tests and shear tests were made and studied to evaluate the mechanical properties of the material. In order to generate testing data, virtual tensile testing simulations were carried out with mesh sensitivity (30636 nodes and 30151 elements) in necking zone, as shown in Figure 1a. This high mesh resolution around necking zone is required to capture the steep gradients in pressure and stress tri-axility, etc. A yield curve is defined to consider effect of strain rate due to dynamic event and to consider the deformation mechanism (Figure 1).

The deformation of spot weld in HSS steel were numerically investigated under the relevant loads tension, shearing and bending

*Corresponding author: Sachin Patil, Wichita State University, Wichita-67208, USA, Tel: +13162001716; E-mail: sachinpatil97@gmail.com

Received August 26, 2014; Accepted November 11, 2014; Published November 19, 2014

Citation: Patil S, Lankarani HM (2014) Simulation Study of Spot Weld Material Configurations for Crash Analysis. J Appl Mech Eng 4: 149. doi: 10.4172/21689873.1000149

Copyright: @ 2014 Patil S, et al. This is an open-access article distributed under the terms of the Creative Commons Attribution License, which permits unrestricted use, distribution, and reproduction in any medium, provided the original author and source are credited. 


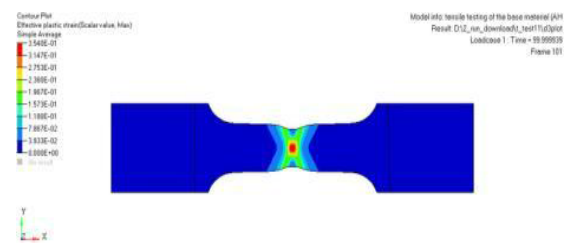

(a)

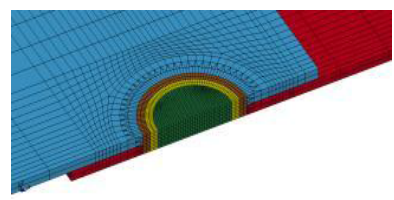

(b)

Figure 1: (a) FE simulations of tensile tests on smooth flat specimens, (b) Detail meshing of weld zone.



(a)

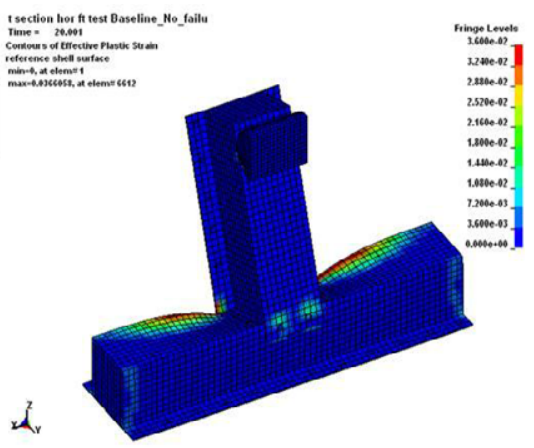

(b)

Figure 2: (a) Simulation setup of T-joint specimen, (b) Baseline spot weld model behavior.

specimens to develop reference model for validation and to avoid high costs for experimentation. Different properties are needed to consider for different zones to predict plastic flow localization and failure in steel spot weld. Failure strains are scaled to maintain the same strain energy to fail in various regions [17]. The spot welds are modeled by using fine solid mesh, as shown in Figure 1b, to analyze the localized deformation. Fine solid mesh allows one to consider spot weld geometry and hardness gradient of its material [18]. This approach is also suitable for the spot welds rupture, which will be modeled in the crash analysis by element elimination. Safer car with improved spot weld rupture definition will provide realistic results compared to physical situation. Brittle fracture produces disastrous consequences as it occurs without warning. This necessitates that we propose a proper failure damage model in this study.

To demonstrate the proposed approach, simulation results of high strength steels (EHSS) for lap-shear and coach peel specimens were used $[19,20]$. Characterization and deformation relevant to weld specimen loading were analyzed for the assessment of weld failure. The failure loads were used as the reference loads to determine the loads applied for other tests such as the fatigue tests, torsion test, etc. Vonmises stress and plastic strain experienced by the weld as well as strain rate corresponding to materials defined in various regions of weld were validated in terms of output result. This suggests that the predicted material constitutive laws using the inverse FE modeling for different zones is accurate. The deformation and failure behavior of weld joints were investigated on small scale specimens under tension and shear loading and KS-2 loading [21]. Spot weld models are developed in FE code LS-Dyna and its parameters identified [20-22].

\section{T-Section Component Case Study}

A comprehensive case study was conducted to demonstrate the proposed failure models of a spot weld under impact loading conditions. A simplified model of the joint was proposed that enables the user to describe the global response for a component level study. The $\mathrm{T}$-joint specimens were used for the stress in the transverse direction and under load speeds simulating of $1 \mathrm{~m} / \mathrm{s}$. For this purpose, a sliding mass in the amount of $192 \mathrm{~kg}$ was identified to realize the failure of spot welds [23] as shown in Figure 2.

A direct method of determining modeling parameters of spot weld from component test data for characterization and deformation modes is carried out. In the baseline model, welds are modeled using MAT_ SW. Weld Failure criteria judged on the basis of normal and shear stress interaction. In baseline analysis, artificial nature of contact forces disturbs the internal spot weld forces and stresses. Post deformation in baseline loading unable to capture deformation in the test however average peak force correlates well. There is failure of shell elements due to high localized strain without any failure of spot welds causing unphysical deformation. In order to capture deformation modes as per test, new spot weld model proposed. Validation of simulation model was done as described in the following section. The simulations were compared out with new spot weld parameters as shown in Figure 3. Flange element failure delayed in the new spot weld model due to tail elongation of weld. This help to improve energy absorption of component comparatively. Overall failure of few heavily loaded spot welds at early stage is circumvented, which observed in baseline analysis. Material model identify failure due to MAT_100_DA card defined .Damage in weld initiated is the function of failure function defined in the FE program Ls-Dyna. Identification of the material parameters for the elastic-plastic region including damage and failure is an iterative process to follow physical testing (Figure 3).

Comparing with the baseline model, the main failure mode was 


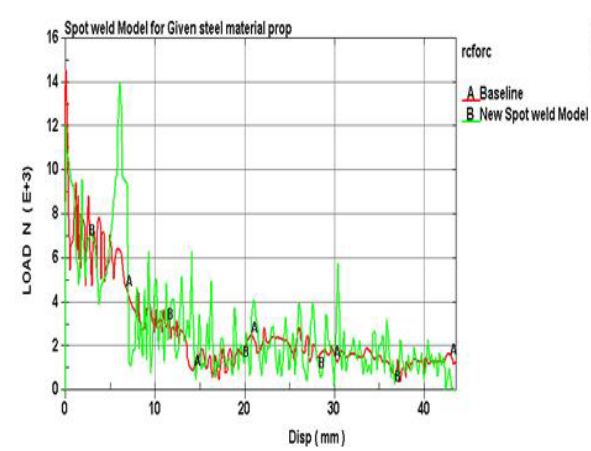

(a)

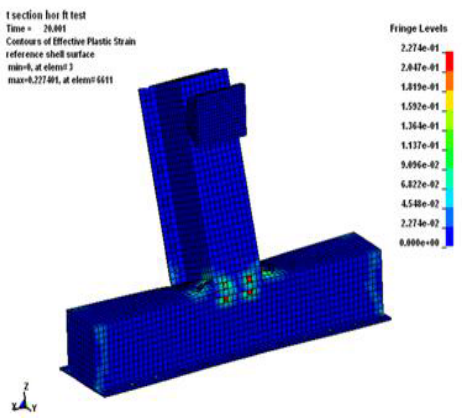

(b)

Figure 3: (a) Force response of simulation loading (Baseline and New spot weld), (b) New spot weld post deformation.

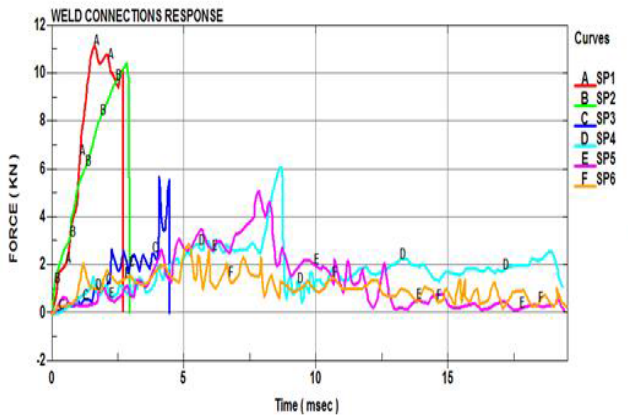

(a)

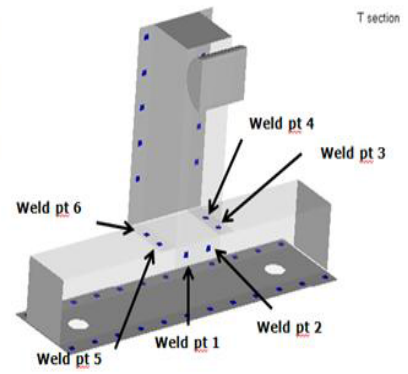

(b)

Figure 4: (a) Local spot weld forces from the simulation, (b) location of spot weld on specimen.



(a)

(b)

Figure 5: Comparison of post deformation (a) New spot weld simulation loading (b) Experimental loading.

encountered for weld on front and side of vertical rail. The force amplitude for these welds is between $2 \mathrm{kN}$ and $12 \mathrm{kN}$, which avoids tearing of sheet metal with tail formation of these spot welds (Figure 4). High strain was also observed in this region of weld. This is a more realistic deformation when compared to the physical test. The representation of the local spot weld forces from the simulation under a loading rate of $1 \mathrm{~m} / \mathrm{s}$ and a slide mass of $192 \mathrm{~kg}$ are shown in Figure 4 below.

In macroscopic scale, the mechanical performances of this new steel configuration spot weld are excellent in term of energy absorption. The final total internal energy of the T-joint rail component with new spot weld model is $127 \mathrm{~kJ}$ which is greater than baseline $117 \mathrm{~kJ}$. Initial lower peak load implies a better performance of the energy collapsible structure in terms of safety design. Oscillations in the calculated force curve also occur. These oscillations are caused by the immediate removal of the hexahedron being reached caused the failure, since the elimination of the stored elastic energy at the area around the spot weld is suddenly released. It is clear that the behavior of the forcetime curves from the simulation produces lesser peaks compared with experiment after the first force peaks. The force levels through vary little from each other. This suggests that on a good set of failure criteria close. The performance can be grown in individual spot weld forces, with mechanical properties comparable to experimental investigation carried out by literature even though the material involving spot weld differs. Figure 5 shows the post deformation of specimen in this simulation study as well as experimental loading [23]. It can be seen that the deformation pattern is comparable to the experiment 
Citation: Patil S, Lankarani HM (2014) Simulation Study of Spot Weld Material Conigurations for Crash Analysis. J Appl Mech Eng 4: 149. doi:10.4172/2168-9873.1000149

on similar grade steel. A considerable amount of experiments have been performed to investigate the failure behavior of spot weld in similar setup by [23-25]. In general, new spot weld model prediction is on the conservative side and these spot weld models have been well characterized by this component model. The material data for the vehicle spot weld simulation can be adjusted to fit the results from this component simulation (Figure 5).

\section{Conclusion}

In this study, spot weld material configurations are modeled and characterized for structural parts analysis. From this simulations, it was observed that local joint fracture can make a significant contribution to the overall crash performance. Highly-detailed mesh of spot welds in this study help to reproduce local properties. More detail weld model can represent detailed local effect, but this may violate time step in full vehicle or component crash analysis. For this reason only representative spot weld models can be utilized. A failure of spot-welds can globally change crash behavior, of which the neglect of spot welds failure leads to altered energy absorption. Thus an improved design of the connection zones fuels the hope to enhance crashworthiness performance. The qualitative behavior of the force response curves and the deformation behavior of the T-joint specimens were well simulated. A new spot weld model material configurations to evaluate spot weld response enables vehicle engineers to design a more consistent vehicle by providing precise prediction of weld strength and performance.

\section{Acknowledgment}

The authors would like to acknowledge participants of the research project coordinated by the Auto/Steel Partnership (AS/P) and FOSTA.

\section{References}

1. Heubrandtner T, Rangger G, Scherjau D (2005) "Advanced spotweld failure modelling based on Trefftz formulation." 4th LS -DYNA Anwenderforum, Bamberg, Germany.

2. Seeger F, Feucht M, Frank T, Keding B, Haufe A (2004) An Investigation on Spot Weld Modelling for Crash Simulation with LS -DYNA. 4 th LS-DYNA Forum. Bamberg, Germany.

3. Seeger F, Feucht M, Dumitru G, Graf T (2008) Enhancement of Spot Weld modeling using MAT_100_DAI. $7^{\text {th }}$ LS-DYNA Forum. Bamberg, Germany.

4. Nakayama E, Fukumoto M, Miyahara M, Okamura K, Fujimoto H, et al. (2006) "Fatigue Strength Prediction of Spot -Welded Joints Using Small Specimen Testing" Corporate Research and Development Laboratories, Fuso-Cho, Amagasaki, Hyogo, Japan.

5. Sebastian B, Sommer S (2012) Characterization and modeling of fracture behavior of spot welded joints. $11^{\text {th }}$ Ls-dyna Forum, Ulm.

6. Ha JW, Song JH, Huh H, Lim JH, Park SH (2008) Dynamic material properties of the heat -affected zone (haz) in resistance spot welding. 5800-5806.

7. Zhang SC (1997) Stress intensities at spot welds. International Journal of Fracture 88: 167-185.

8. Zhang SC (1999) Stress intensities derived from stresses around a spot weld. International Journal of Fracture 99: 239-257.

9. Nakayama E, Okamura K, Miyahara M, Yoshida M, Fukui K, et al. (2003) Prediction of Strength of Spot -Welded Joints By Measurements of Local Mechanical Properties. SAE Technical Paper.
10. Lee YL,Wehner TJ, Lu M-W, Morrissett TW, Pakalnins E (1998) Ultimate Strength of Resistance Spot Welds Subjected to Combined Tension and Shear. Journal of Testing and Evaluation 26: 213-219.

11. Yuh J Chao (2003) "Ultimate Strength and Failure Mechanism of Resistance Spot Weld Subjected to Tensile, Shear, or Combined Tensile/Shear Loads". Journal of Engineering Materials and Technology.

12. Deng X, Chen W, Shi G (2000) Three-dimensional finite element analysis of the mechanical behavior of spot welds. Finite Elements in Analysis and Design 35: 17-39.

13. Schweizerhof K, Schmid W, Klamser H (2000) Improved Simulation of Spot welds in Comparison to Experiments using LS-DYNA. 18th CAD-FEM Users' Meeting International Congress on FEM Technology. Friedrichshafen, Germany.

14. Wang J, Xia Y, Zhou Q, Zhang J (2006) Simulation of Spot Weld Pullout by Modeling Failure Around Nugget. SAE Technical Paper.

15. Advanced High Strength Steel (2005) Application guidelines, International Iron \& Steel Institute, committee on automotive applications.

16. High Strength Low Alloy Steel (2005) The U.S. Steel Automotive Group Grade and Product Reference. United States Steel Corporation.

17. Zhili Feng, Srdjan Simunovic "Impact Modeling and Characterization of Spot Welds" ORNL and Auto/Steel Partnership report.

18. Song JH, Huh H, Kim HG, Park SH (2006) "Evaluation of the Finite Element Modeling of A Spot Welded Region For Crash Analysis" International Journal of Automotive Technology 7: 329-336.

19. Nguyen NT, Kim DY, Song JH, Kim KH, Lee IH, et al. (2012) "Numerical Prediction of Various Failure Modes in Spot welded Metals." International Journal of Automotive Technology 13: 459-467.

20. Oh CS, Kim NH, Kim YJ, Baek JH, Kim YP, et al. (2011) "A Finite Element Ductile Failure Simulation Method using Stress-Modified Fracture Strain Model." Engineering Fracture Mechanics 78: 124-137.

21. Hahn O, Wißling M, Klokkers F (2009) Determination of true Characteristic values for bolted and riveted sheet metal stamping compounds under impulsive load. EFB Research Report No. 297

22. Sachin Patil (2014) "Modeling and Characterization of Spot Weld for Crash Analysis" Dissertation. Wichita State Univ.

23. Michael Oeter, Kenan Özdem, Ortwin Hahn "Experimental determination of Structural behavior of spot welded Components made of sheet steel connections" Frankfurt, Germany.

24. Sebastian burget, Silke Sommer (2012) Characterization and modeling of fracture behavior of spot welded joints. $11^{\text {th }}$ Ls-dyna Forum, Ulm.

25. LSTC, LS-DYNA Keyword Manual, 971. 